\title{
PHONOLOGICAL SKILLS AS PREDICTOR OF READING SUCCESS: AN INVESTIGATION OF EMERGENT BILINGUAL NORTHERN SOTHO/ENGLISH LEARNERS
}

\author{
Carien Wilsenach \\ University of South Africa
}

The relationship between phonological skills and reading has not been studied extensively in the African languages spoken in South Africa. This study focuses on phonological skills and reading in emergent bilingual Northern Sotho/English learners. Fifty Grade 3 learners (all native speakers of Northern Sotho) were tested on non-word repetition skills, syllable awareness, phonological working memory and reading. The learners fell into two groups: group 1 attended a school where English was the medium of instruction from the first grade, while group 2 attended a school where literacy instruction took place in Northern Sotho for the first three years of schooling. The results indicate that there is a significant correlation between phonological skills and reading in Northern Sotho. Furthermore, group 2 performed significantly better on all of the phonological measures (with the exception of phonological working memory) and reading measures. The findings suggest that a complete lack of mother tongue instruction can influence phonological and literacy development negatively. The study also suggests that the absence of mother tongue literacy instruction causes stagnation in the development of phonological processing skills in the mother tongue.

\section{INTRODUCTION}

Compared to international standards, South African learners reach lower than expected literacy levels during their primary school years (Mothibeli, 2005). South African learners performed dismally in the 2006 PIRLS (Progress in International Reading Literacy Study) assessments (Howie, Venter, Van Staden, Zimmerman, Long, Du Toit, Scherman and Archer, 2008) and more recently results from the Annual National Assessment indicated that Grade 3 and Grade 6 learners achieved averages of 35\% and 28\%, respectively, in literacy (Department of Basic Education, 2011). Education in South Africa is characterised by a system in which English is commonly used as the Language of Learning and Teaching (LoLT) (Hunt, 2007). Where schooling does occur in African languages it does so for a 3-4year period, after which learners switch to English. Thus, most learners acquire literacy either solely in an Additional Language (AL), or via a bilingual system in which they initially learn to read in an African language and then continue their education in an AL (Pretorius and Mampuru, 2007).

A range of phonological skills, including Phonological Awareness (PA), Phonological Working Memory (PWM) and general phonological processing, is needed for the acquisition 
of reading skills (Perfetti, 1994). Despite this knowledge, the effect of poorly developed first language (L1) phonological skills on literacy acquisition has not been studied widely in South Africa. The present study investigated the relationship between phonological skills and reading in emergent bilingual Northern Sotho/English children. ${ }^{1}$ As such, it contributes to existing knowledge about the relationship between phonological skills and reading in African languages.

\section{THEORETICAL BASIS PHONOLOGICAL SKILLS AND LEARNING TO READ}

Different dimensions of PA exist (Brady and Shankweiler, 1991). These dimensions are typically referred to as phoneme (or phonemic) awareness, syllable awareness and onset-rime awareness. Phoneme awareness refers to the ability to detect the constituent phonemes within a word (i.e. cat can be segmented into three phonemes $(c-a-t)$, whereas syllable awareness refers to a similar sensitivity but on a different level (i.e. kitten can be segmented into two syllables ( $k i$-ten). Onset-rime awareness refers to the ability to separate a word's onset (' $c$ ' in cat) from its rime ('at' in cat). Easier dimensions of PA, such as the ability to synthesise phonemes into syllables and to detect the number of syllables in a word facilitate and predict the first stages of reading acquisition (Perfetti, Beck, Bell and Hughes, 1987). More complex levels of PA, such as phoneme segmentation and onset-rime awareness, are typically poorly developed in first graders who start to read. Phoneme awareness, which relies on analytic skills, does not reliably predict reading progress in the first grade; rather, phoneme awareness abilities are initially predicted by early progress in learning to read and only later on do they start to predict further success in reading (Perfetti, 1994; Shankweiler \& Fowler, 2004). PA skills are shaped by the phonological structure of a language - children learning to read in Italian or Turkish, for example, show better syllable awareness than children learning to read English or French (Alcock et al., 2010).

Apart from PA, phonological skills such as PWM and general phonological processing also contribute to and predict reading acquisition. PWM forms a subcomponent of working memory and consists of a phonological store (that briefly retains all verbal information that has to be processed or produced) and an articulatory loop (that rehearses and invigorates the verbal information in the phonological store to ensure that it doesn't fade away before being processed) (Baddeley, 1999 \& 2003). PWM skills play an essential role in learning to read, as the ability to fragment a word into its constituent phonemes requires the working memory system to store the entire phonological representation of the word while the constituent phonemes are first disjointed and then sequenced back into the correct order by the learner (Nithart, Demont, Majerus, Poncelet \& Leybaert, 2011). The quality of an individual's PWM is also thought to affect the accuracy and efficiency with which the phonological representations of words are converted from short-term to long-term memory. Poor PWM may lead to unstable phoneme representations in long-term memory, which in turn may negatively affect the acquisition of the phoneme-grapheme correspondences of a language, which is crucial for learning to read. PWM is typically assessed with digit and word span tasks and with non-word repetition (NWR) tasks.

Even though NWR tasks are often used to measure PWM, such tasks measure a slightly different aspect of phonological memory than digit/word span tasks. Nithart et al. (2011) explain the different aspects of phonological memory as follows: it has a short-term memory 
component, a long-term phonological knowledge component and a memory for serial order component. On the one hand, NWR is believed to entail the encoding, storing and retrieving of a new phonological form with an individual being asked to recall a "word" that at best mimics existing phonological structures. Digit and word span, on the other hand, entail the encoding, storing and retrieving of phonological forms that already have a stored form in long-term memory. Thus, one could argue that NWR represents a clearer view of an individual's 'online' phonological processing capacity (De Bree, 2007).

\section{PHONOLOGICAL SKILLS AND READING IN AFRICAN LANGUAGES}

Previous research on the relationship between phonological abilities and literacy in South Africa focused on emergent bilingual Zulu/English learners. Soares De Sousa, Broom and Fry (2010) investigated the effects of Zulu and English PA on the acquisition of English spelling skills in learners that speak Zulu as a L1 but require literacy in English only. Zulu PA skills were related to spelling in both Zulu and English, but more of the PA levels tested related to English spelling than to Zulu spelling. Soares De Sousa and Broom (2011) studied the relationship between English PA and reading in monolingual English and bilingual Zulu/English learners. PA was associated with both word reading and reading comprehension, but different levels of PA predicted reading tasks in L1 English compared to L2 English.

Elsewhere in Africa, Veii and Everatt (2005) investigated predictors of word reading among Grade 2-5 Herero-English bilingual children. Phonological skills in Herero and English (such as PA and NWR) reliably predicted word reading in both languages. The researchers further established that learners progressed faster in Herero than in English, which they attributed to the fact that Herero is orthographically more transparent than English. The ability to read letters have been associated with a variety of PA levels in Swahlili (Alcock, Ngorosho, Deus and Jukes 2010). Alcock et al. (2010) reported that illiterate Swahili children possessed some implicit phonological awareness (such as counting syllables and repeating non-words) but not necessarily explicit phonological awareness (such as phoneme awareness) which is more associated with learning to read.

\section{READING IN BILINGUAL CHILDREN}

The processes involved in acquiring reading skills in more than one language (or in an AL only) are not fully understood (Deacon and Cain, 2011). Scholars working in the field of bilingual literacy aim to discover whether factors that predict individual reading differences in a L1 also predict reading outcome in a L2/AL, whether metalinguistic knowledge (such as PA) transfer to and assist in the process of acquiring literacy in an AL and whether the phonological structure of a learner's L1 influences phonological development in the AL.

Several theories have been proposed to address these research problems. The Linguistic Interdependence Theory proposes that those aspects of linguistic knowledge that is required for learning to read will transfer automatically from the L1 to the L2/AL and that they do not have to be relearned in the AL. It is generally thought that the direction of transfer is from the L1 to the L2/AL, but the theory does allow for bidirectional transfer of metalinguistic skills (Cummins, 2000). The Linguistic Threshold Hypothesis (Bernhart and Kamil, 1995) suggests that transfer of L1 literacy skills to the L2/AL only occurs if the learner has reached a 
threshold level of proficiency in the L2/AL. A lack of competence in the L2 will prevent the 'automatic' use of literacy skills acquired in the L1 when learning to read in the L2/AL. The Central Processing Hypothesis (Geva and Siegel, 2000) is related to Cummins' theory and assumes that literacy acquisition does not depend on the nature of the language in which a learner is receiving literacy instruction. Rather, common underlying linguistic and cognitive/psychological processes (i.e. PA, lexical ability, working memory and automaticity) influence the development of literacy across all languages. The Script Dependent Hypothesis states that the development of literacy is influenced by the orthographical transparency of a language, making it easier to acquire literacy in a language with a transparent orthography (where phoneme-grapheme correspondences are one-to-one) than in a language with an opaque orthography (where many variations in phoneme-grapheme correspondences exist). The hypothesis suggests that bilingual learners will progress faster in reading in the more transparent of their languages (Paulesu, 2006).

\section{RESEARCH SETTING}

This research was undertaken in two primary schools in a suburb on the outskirts of Pretoria. Several African languages are spoken in the research area, but Northern Sotho is the main home language. Schooling in Northern Sotho is available from Grades R-3 in some schools within the research area. After Grade 3, the LoLT changes to English. At the time of this study, both schools were involved the research project Reading is FUNdamental (Pretorius and Mampuru, 2007). As a result, both schools had functioning libraries with between 4000 and 5000 books each and teachers from both schools attended workshops aimed at developing their literacy teaching skills. Thus, though the schools were poor, they had equal access to the basic resources required for teaching literacy to children.

\section{THE NORTHERN SOTHO LANGUAGE}

Northern Sotho shares the characteristic agglutination of other Bantu languages and shares many of the typical grammatical features of Southern Bantu languages. ${ }^{2}$ The following features of Northern Sotho are relevant for this study:

1. Northern Sotho is a syllable timed language: the duration of syllables in words is perceived to be equal. Syllables receive approximately equal stress and generally lack reduced vowels (Coetzee and Wissing, 2006).

2. Northern Sotho has a simple phonological structure: words contain many open syllables and few consonants clusters. Monosyllabic words are avoided (http://en.wikipedia.org/wiki/Sotho_phonology).

3. Northern Sotho nouns are marked with prefixes in order to group them into noun classes (http://africanlanguages.com/northern_sotho/).

4. Northern Sotho has a transparent orthography (Van Rooy and Pretorius, 2013).

\section{HYPOTHESES AND RESEARCH QUESTIONS}

The following specific research questions will be addressed: 
1. Does a lack of L1 literacy instruction negatively affect the development of phonological and reading skills in emergent bilingual Northern Sotho/English children?

2. Do Northern Sotho phonological skills predict reading outcome in emergent bilingual Northern Sotho/English children?

3. Do emergent bilingual Northern Sotho/English children progress faster in reading in the orthographically more transparent of their two languages?

Since the relationship between PA and literacy is reciprocal, it is hypothesised that children who received no formal Northern Sotho instruction will display poorer Northern Sotho PA and reading skills. Secondly, it is hypothesised that Northern Sotho PA and phonological processing skills will predict reading outcomes in Northern Sotho and in English. Finally, the researcher predicts that learners who received literacy instruction in both Northern Sotho and in English will progress faster in Northern Sotho, given the more transparent nature of Northern Sotho orthography.

\section{PARTICIPANTS}

The participants were 50 Northern Sotho children in Grade 3 who came from similar socioeconomic backgrounds, had equal learning opportunities and indicated that Northern Sotho was their L1. The participants were divided into two groups based on the language policy of their school. Group 1 consisted of 25 children (11 male; mean age 8;9) who attended a school where Northern Sotho was the LoLT from grade 1-3 (English was introduced as a subject in grade 2). Group 2 consisted of 25 children (15 male; mean age 9;0) who attended a school where English was the LoLT from grade 1 onwards.

Informed consent to test learners was obtained from the relevant authorities before the study. Prior to testing, each individual learner also gave his/her assent to participate in the study.

\section{MATERIALS AND PROCEDURE: PHONOLOGICAL WORKING MEMORY}

PWM was tested with a digit span forwards task (similar to tasks used in IQ tests such as the WISC-R and the WAIS-III). The digit span task was presented orally in English, using a consistent speaking rate. The rationale for using English was that it was unclear how much exposure the participants in group 2 have had to the Northern Sotho equivalents of the digits $1-10$, whereas it was quite certain that the participants from group 1 would have had ample exposure to these digits in English. The first string that had to be recalled was two digits long (and was used as a practice item) while the longest strings in the task contained seven digits. The digit "seven" (7) was excluded on the basis that it contains two syllables, and is thus longer (and potentially requires more processing) than the rest of the digits. Each level in the task consisted of three test items. For example, the researcher would orally present a digit string such as " 258 " and the leaner's task was to repeat the string back (also orally). The task was discontinued when a child got two items wrong at any given level. The task was scored online by the researcher and a raw score (which equalled the number of correct repetitions) was calculated for each participant. 


\section{PHONOLOGICAL AWARENESS}

PA was assessed using a Northern Sotho syllable awareness task. ${ }^{3}$ There are no formal, standardised tests to assess PA in Northern Sotho - the materials used in this task were developed as part the Reading is FUNdamental project (Pretorius and Mampuru, 2007). A PA awareness task was tailor-made for this project - the task was not meant to be a diagnostic tool and should not be confused with tests that aim to diagnose language impairment in individual learners. In the present study, the task was used as a research tool that measured levels of PA across different groups of learners. The syllable deletion task used here could be compared to syllable deletion tasks found in standardised English PA tests, such as the CTOPP (Comprehensive Test of Phonological Processing) and the PAT 2 (The Phonological Awareness Test 2) and the author is satisfied that the task is a valid and reliable measure of syllable awareness. The syllable deletion task contained the following three conditions:

1. Initial syllable deletion

2. Final syllable deletion

3. Middle syllable deletion

The task was administered as follows: each learner was asked to repeat a pre-selected Northern Sotho word, such as bolelo ("Say "bolelo"'). Following this the learner was requested to repeat the word, but to delete a particular syllable ('Now say it again but don't say "/bo/"" - an example of initial syllable deletion). The same procedure was followed for all three conditions (i.e. "Say "morago"... don't say "/go/" (final syllable deletion) and 'Say "polelo"... don't say "/le/"” (middle syllable deletion). Refer to appendix A for a complete list of the items used in this task.

Participants were trained with items similar to the items in the first condition. The training was discontinued once the researcher was entirely satisfied that the participants understood the task. After the training phase, the test phase, consisting of 9 items ( 3 items per condition) commenced. The researcher scored the task online, awarding one point for each correct response. Thus, every participant received a raw score out of 9, which was transformed into a percentage for the PA task as a whole.

\section{PHONOLOGICAL PROCESSSING}

Phonological processing was assessed with a novel Northern Sotho non-word repetition (NWR) task. The non-words were created following the criteria in Dollaghan and Campbell (1998). Thus, neither the non-words nor their constituent syllables corresponded to lexical items - the non-words included phonemes and syllable types which are acquired early - the non-words included phonemes that are acoustically salient and the words were phonotactically possible. The Northern Sotho non-words started with 'prefixes' similar to those used in Northern Sotho to mark specific noun classes. The task consisted of 1 practice and 16 test items. The test items varied in length from four to seven syllables. The reason for including items of different lengths in NWR tasks is that longer words require more processing, and deficiencies in phonological processing are typically observed more in the repetition of long words than in the repetition of short words. The stimuli for the NWR task were pre-recorded by an L1 speaker of Northern Sotho to ensure that their auditory presentation to participants happened at a consistent rate and with consistent intonation and accuracy. The non-words were presented to a learner one after the other and after hearing the 
recording of a particular item the learner was requested to repeat the non-word orally. Participants were rewarded after each repetition with a picture card of a Pokemon character, which fit onto a big poster - the learners had to match the character on the card with the character on the poster. The playful manner of the task ensured that the learners stayed focused and motivated.

Responses were digitally recorded and transcribed later. Each participant was awarded a raw score and Percentage Phoneme Correct (PPC). The raw score (out of 16) was calculated by awarding 1 point for each response that was entirely correct. The PPC was calculated by adding up the number of correct phonemes that each response contained, i.e. if a participant repeated the non-word /sepokari/ as /sebokadi/, s/he was rewarded a phoneme score of 6/8, which equals a PPC score of 75 . Using the individual scores, mean raw and PPC scores were calculated for each group. Refer to appendix A for a complete list of the items used in this task.

\section{READING ASSESSMENT}

There are no standardised reading assessments in Northern Sotho. Firstly, reading skills were assessed using tailor-made Northern Sotho and English word lists and Northern Sotho and English texts. Both word lists consisted of 30 items, progressed from easy to difficult, were deemed age-appropriate in terms of vocabulary demand and had previously been used in the Reading is Fundamental project (Pretorius and Mampuru, 2007). This aspect of the reading assessment was labelled Word Recognition in the data analysis. The researcher scored online the number of words that each participant read correctly in both languages. Secondly, participants had to read from Northern Sotho and English readers. The author scored on-line the number of words that each participant read correctly in both languages in the course of 1 $1 / 2$ minutes. This aspect of the reading assessment was labelled Fluent Reading in the data analysis.

The research design could be described as cross-sectional: participants were tested once during the months of August and September at their schools. The test battery described above was administered individually in a quiet space. All data was collected by the author.

\section{RESULTS: GROUP DIFFERENCES}

Group differences were established by calculating mean raw scores (for PWM and fluent reading) and mean percentages (for PA, phonological processing and word recognition). A Kolmogorov-Smirnov goodness of fit test indicated that the data was distributed normally. Statistical significant differences were detected by conducting an independent samples t-test, with the phonological and reading measures as the dependent variables and group as the independent variable. Table 2 provides a summary of the obtained mean scores, the standard deviations, the $t$-statistic and $p$-values. 
Table 2. Mean raw score for PWM, Mean percentages for Phonological awareness, Phonological processing and Word recognition and Mean raw score for fluent Northern Sotho and English reading.

\begin{tabular}{|c|c|c|c|c|c|c|}
\hline \multirow[b]{2}{*}{ Measures } & \multicolumn{2}{|c|}{$\begin{array}{c}\text { Group 1 } \\
(N=25)\end{array}$} & \multicolumn{2}{|c|}{$\begin{array}{c}\text { Group } 2 \\
(N=25)\end{array}$} & \multirow[b]{2}{*}{$t$} & \multirow[b]{2}{*}{$\underset{\text { (2-tailed) }}{\mathbf{P}}$} \\
\hline & Mean & $(S D)$ & Mean & $(S D)$ & & \\
\hline Phonological working memory & 10.08 & $(2.79)$ & 9.6 & $(2.14)$ & .681 & .499 \\
\hline Phonological awareness & 68.86 & $(21.75)$ & 51.98 & $(36.40)$ & 2.07 & $.044 *$ \\
\hline \multicolumn{7}{|l|}{ Non-word repetition } \\
\hline Raw score & 57 & $(15.65)$ & 39 & $(17.33)$ & 3.85 & $.000 *$ \\
\hline Phoneme percentage correct & 92.13 & $(3.90)$ & 86.66 & $(6.71)$ & 3.52 & $.001 *$ \\
\hline \multicolumn{7}{|l|}{ Reading } \\
\hline Northern Sotho word recognition & 89.33 & $(16.10)$ & 44.27 & $(31.95)$ & 6.29 & $000 *$ \\
\hline English word recognition & 79.33 & $(21.19)$ & 68.80 & $(23.03)$ & 1.68 & .099 \\
\hline Northern Sotho fluent reading & 49.08 & $(21.14)$ & 18.04 & $(16.21)$ & 5.82 & $.000 *$ \\
\hline English fluent reading & 50.45 & $(36.17)$ & 42.92 & (34.79) & .753 & .455 \\
\hline
\end{tabular}

*Significant at the 0.05 level.

\section{PHONOLOGICAL WORKING MEMORY}

The mean raw scores on the digit span task were 10.08 (Group 1) and 9.6 (Group 2). This difference was not significant $(t=.681, \mathrm{p}=.499)$ which suggests that participants from both groups had comparable PWM skills.

\section{PHONOLOGICAL AWARENESS}

A two-tailed t-test indicated that group $1(\mathrm{M}=68.86)$ performed significantly better on the PA task than group $2(\mathrm{M}=51.98)(\mathrm{t}=2.07, \mathrm{p}=.044)$.

\section{PHONOLOGIAL PROCESSING}

The results of the non-word repetition task were analysed on two levels. The first score (a raw score) gave an indication of participants' ability to recall non-words completely correctly. The second score (PPC) gave an indication of the number of phonemes that participants could reproduce correctly. Group 1 performed significantly better than group 2 on both these scores, with a mean raw score of $57 \%$ (compared to $39 \% ; \mathrm{t}=3.8, \mathrm{p}<.000$ ) and PPC score of $92.12 \%$ (compared to $86.6 \%$; $=3.9, \mathrm{p}=.001$ ).

\section{READING}

Group $1(M=89.33)$ performed significantly better $(t=6.29, p<.000)$ on the Northern Sotho word recognition task than group $2(\mathrm{M}=44.2)$. In terms of fluent reading in Northern Sotho, group 1 again significantly outperformed group 2: on average group 1 read 49.08 words correctly within the allocated time whereas group 2 on average managed 18.04 words $(\mathrm{t}=$ $5.82, \mathrm{p}<.000)$. With regard to English reading, group 1 outperformed group 2 in both word recognition and in fluent reading, but the mean differences were not significant. 


\section{CORRELATIONS AND MULTIPLE REGRESSION ANALYSIS}

Pearson's Correlation was used to test the relationship between PWM, PA, phonological processing (i.e. NWR raw score and PPC) and reading. An overview of the observed correlations is presented in table 3 .

In group $1, P W M(\mathrm{r}=.363, \mathrm{p}=.037)$ and the $N W R$ raw score $(\mathrm{r}=.361, \mathrm{p}=.038)$ were positively correlated with Northern Sotho fluent reading. $P A$ was correlated with English fluent reading $(\mathrm{r}=.440, \mathrm{p}=.014)$. None of the phonological measures were significantly correlated with word recognition in either of the languages in this group.

In group 2, $P W M(\mathrm{r}=.444, \mathrm{p}=0.13), P A(\mathrm{r}=.533, \mathrm{p}=.002)$ and $P P C(\mathrm{r}=.339, \mathrm{p}=0.48)$ were all positively correlated with Northern Sotho word recognition. $P A$ was also positively associated with Northern Sotho fluent reading $(\mathrm{r}=.471, \mathrm{p}=.009)$ and with English word recognition $(\mathrm{r}=.571, \mathrm{p}=.001)$. There were no significant correlations between the phonological measures and English fluent reading in group 2.

\section{PREDICTORS OF READING IN EMERGENT BILINGUAL NORTHERN SOTHO/ENGLISH CHILDREN}

Hierarchical multiple regression analyses were performed to discover if the phonological variables measured here could reliably predict reading performance. The data sets were collapsed into a single data set for these analyses. The measures $P A, N W R$ raw score, NWR $P P C$ and $P W M$ was entered into the model as predictor variables. For each of the reading outcomes (i.e. Northern Sotho word recognition, Northern Sotho fluent reading, English word recognition and English fluent reading the phonological predictors were entered as follows: $P A$ was entered at the first stage of each analysis, NWR raw score and NWR PPC were entered at the second stage and $P W M$ was entered at the third stage of each analysis. This hierarchy was based on existing evidence that PA is a robust predictor of reading outcome, while skills like non-word repetition and digit recall often predict less of the variance in reading outcome. An overview of the regression statistics for the relationship between phonological skills and reading in Northern Sotho and in English reading is given in Table 4.

\section{PREDICTORS OF NORTHERN SOTHO READING}

$P A$ significantly predicted Northern Sotho word recognition at every stage of the model. At step $1, P A$ accounted for $27.4 \%$ of the variance in the outcome $\left(\mathrm{R}^{2}=.274 ; \mathrm{SE}=29.13\right)$. Neither of the NWR measures entered in step 2, nor PWM entered in step 3 significantly predicted reading performance of Northern Sotho words; and NWR and PWM explained an additional $10.7 \%$ of the variance in the outcome $\left(\mathrm{R}^{2}=.381 ; \mathrm{SE}=27.78\right.$ at step 3$)$. Regarding Northern Sotho fluent reading, the results indicated that $P A$ reliably predicted reading performance at step 1 and step 2 of the model (explaining 18.2\% of the variance at step 1, $\mathrm{R}^{2}$ $=.182 ; \mathrm{SE}=22.26)$. NWR raw score significantly predicted Northern Sotho fluent reading at step 2, explaining an additional $16.2 \%\left(\mathrm{R}^{2}=.344 ; \mathrm{SE}=20.36\right)$ of the variance in the outcome. After entering $P W M$ at step 3, $P A$ no longer significantly predicted fluent reading. NWR raw score remained a significant predictor of fluent reading in Northern Sotho at step 3 of the analysis. 
Table 3. Correlations between phonological measures and reading

\begin{tabular}{|c|c|c|c|c|c|c|c|c|}
\hline & \multicolumn{4}{|c|}{ Group 1 (Northern Sotho Group) } & \multicolumn{4}{|c|}{ Group 2 (English group) } \\
\hline & $\begin{array}{l}\text { NS Word } \\
\text { Recognition }\end{array}$ & $\begin{array}{l}\text { NS } \\
\text { Text }\end{array}$ & $\begin{array}{l}\text { English Word } \\
\text { Recognition }\end{array}$ & $\begin{array}{c}\text { English } \\
\text { Text }\end{array}$ & $\begin{array}{l}\text { NS Word } \\
\text { Recognition }\end{array}$ & $\begin{array}{l}\text { NS } \\
\text { Text }\end{array}$ & $\begin{array}{l}\text { English Word } \\
\text { Recognition }\end{array}$ & $\begin{array}{c}\text { English } \\
\text { Text }\end{array}$ \\
\hline PWM & .063 & $.363^{*}$ & .186 & .263 & $.444 *$ & .291 & .117 & .062 \\
\hline Phonological awareness & .202 & .207 & .321 & $.440 *$ & $.553 * *$ & $.471 * *$ & $.571 * *$ & .156 \\
\hline NWR Raw score & .160 & $.361 *$ & .098 & .186 & .262 & .297 & .146 & .106 \\
\hline NWR PPC & .097 & .203 & .090 & .116 & $.339 *$ & .254 & .164 & .033 \\
\hline
\end{tabular}

$* \mathrm{p}<.05 ; * * \mathrm{p}<0.01(95 \%$ confidence interval)

Table 4. Overview of regression analyses

\begin{tabular}{|c|c|c|c|c|c|c|c|c|c|c|c|c|c|}
\hline \multirow{2}{*}{\multicolumn{2}{|c|}{ Step 3}} & \multicolumn{3}{|c|}{$\begin{array}{c}\text { Northern Sotho } \\
\text { Word Recognition }\end{array}$} & \multicolumn{3}{|c|}{$\begin{array}{l}\text { Northern Sotho } \\
\text { Fluent Reading }\end{array}$} & \multicolumn{3}{|c|}{$\begin{array}{c}\text { English } \\
\text { Word Recognition }\end{array}$} & \multicolumn{3}{|c|}{$\begin{array}{l}\text { English Fluent } \\
\text { Reading }\end{array}$} \\
\hline & & $\mathrm{B}$ & SE & Beta & $\mathrm{B}$ & SE & Beta & B & $\mathrm{SE}$ & Beta & B & SE & Beta \\
\hline & (Constant) & -79.55 & 90.05 & & 25.18 & 66.61 & & 58.11 & 65.43 & & 135.13 & 112.75 & \\
\hline 1 & Phonological awareness & .46 & .15 & $.41 *$ & .21 & .11 & .26 & .39 & .11 & $.52 * *$ & .298 & .194 & .25 \\
\hline 2 & NWR Raw score & .31 & .37 & .17 & .66 & .27 & $.50 *$ & .08 & .27 & .07 & .50 & .46 & .27 \\
\hline 2 & NWR Phoneme \% correct & 1.33 & 1.22 & .24 & -.46 & .90 & -.11 & -.05 & .89 & -.01 & -1.62 & 1.53 & -.29 \\
\hline
\end{tabular}




\section{PREDICTORS OF ENGLISH READING}

PA significantly predicted English word recognition at each step of the model and accounted for $25.7 \%$ of the variance in the outcome $\left(\mathrm{R}^{2}=.257, \mathrm{SE}=19.63\right)$. NWR and PWM did not explain any additional variance $\left(\mathrm{R}^{2}=.263, \mathrm{SE}=20.19\right)$. With regard to English fluent reading, $P A$ significantly predicted the reading outcome at step $1(\mathrm{t}=2.02 ; \mathrm{p}=.049)$, but after entering NWR and PWM in the model it no longer reliably predicted English fluent reading.

\section{DISCUSSION}

This study investigated the development of phonological skills in two populations of bilingual Northern Sotho/English children. Specifically, performance on PWM, PA (measured as syllable awareness) and phonological processing was investigated. The rationale was that the role of poorly developed L1 phonological skills has not been adequately investigated in South Africa, where learners systematically underperform in literacy assessments. The first group (the Northern Sotho group) attended a school where the LoLT was Northern Sotho from Grade 1-3. The second group (the English group) attended a school where English was the LoLT from grade 1 onwards. The three research questions formulated at the outset of the study will be discussed in turn.

The first question was: Does a lack of L1 literacy instruction negatively affect the development of phonological and reading skills in emergent bilingual Northern Sotho/English children?

Performance on the phonological working memory task indicated that the basic ability of the learners to decode, store and encode familiar phonological information was comparable across groups. This finding was important as it i) gave (admittedly limited) evidence that the groups were similar in terms of cognitive functioning and ii) was safe to assume that the groups had the same short-term memory capacity to handle more demanding phonological tasks, such as syllable deletion and non-word repetition. The Northern Sotho learners had better PA skills on the syllable level than the English group. These learners showed an increased ability to delete syllables from Northern Sotho words and to synthesise the remaining constituent syllables into new phonological strings. Thus, even in a syllable timed language like Northern Sotho, where syllables are particularly highlighted in spoken language, awareness of this phonological unit is enhanced significantly when children learn to read in the language. The NWR task indicated that the Northern Sotho group was significantly better at decoding, storing and retrieving new phonological information in the L1. Repeating non-words is normally seen as a cognitive, rather than an acquired skill. Even so, the performance of the English group suggests that general L1 phonological processing abilities weaken or stagnate when children do not receive literacy instruction in the L1. Becoming literate in one's L1, it seems, not only enhances metalinguistic skills such as PA, but also cognitive skills such as online phonological processing.

The Northern Sotho group outperformed the English group on all of the reading measures. The Northern Sotho group read significantly better in Northern Sotho on both word and fluent text level and also obtained higher scores on the English reading measures (this despite the fact that they had less exposure to English than the English group). This finding supports the Linguistic Interdependence Theory in that the Northern Sotho group seemed to successfully 
transfer those aspects of linguistic knowledge required for learning to read from their L1 to the AL. Furthermore, the results show that the early development of reading skills in L2 English, alongside L1 instruction, is beneficial in emergent bilingual children.

The second research question was: Do Northern Sotho phonological skills predict reading outcome in emergent bilingual Northern Sotho/English children?

In the Northern Sotho group none of the phonological measures correlated significantly with word recognition (in either of the languages). Phonological working memory and the nonword repetition raw score correlated with Northern Sotho fluent reading, while PA was associated with English fluent reading. In the English group, $P W M$ and $P P C$ significantly correlated with Northern Sotho word recognition, PA was significantly correlated with both levels of reading in Northern Sotho and with English word recognition. There were no significant correlations between the phonological measures and English fluent reading.

Hierarchical regression analyses were performed on a collapsed data set to discover whether any of the phonological measures reliably predicted reading outcome. The variables $P A$, phonological processing (i.e. NWR raw NWR PPC score) and $P W M$ were entered into the regression model. Two of these measures significantly predicted reading outcomes in Northern Sotho and in English. PA reliably predicted the learners' performance in reading Northern Sotho words and English words. The regression model suggested that L1 (Northern Sotho) $P A$ was a robust predictor of both L1 and L2 word reading. This finding is similar to those of Veii and Everatt (2005) and Soares De Sousa (2011). Northern Sotho PA further predicted Northern Sotho fluent reading, although not as robustly as word reading. In this particular study, Northern Sotho $P A$ was not a robust predictor of English fluent reading.

The raw score on the NWR task significantly predicted learners' performance in Northern Sotho fluent reading. This is an encouraging finding in that a NWR task is easy to administer and a raw score on the task is easily obtained. Standardising a NWR task for the Sotho language group could benefit educators who need to identify readers at risk for reading failure early on. The diagnostic value of NWR tasks has often been described (as in Bishop, Adams \& Frazier Norbury, 2004) and it could be a useful tool within the South African context. The third measure, PWM, did not predict reading outcomes in either of the two languages.

The final question was: Do emergent bilingual Northern Sotho/English children read better in the orthographically more transparent of their two languages?

The Northern Sotho group read more fluently in their L1 than in their L2, which could cautiously be interpreted as evidence in favour of the Script Dependent Hypothesis, as Northern Sotho is orthographically more transparent than English. ${ }^{4}$ This finding echoes Veii and Everatt (2005) who reported that Herero-English bilingual children progressed more quickly in Herero reading than in English reading.

The present findings suggest that transfer of underlying linguistic knowledge ('knowledge' here refers to phonological awareness and processing skills) does not always happen automatically. The L1 (Northern Sotho) in this study is simpler than the L2 (English), both in terms of phonological structure and of orthographical transparency. According to the Script Dependent Hypothesis, learning to read in Northern Sotho should be relatively easy for Northern Sotho children, even if initial instruction takes place in an AL. However, the English 
group could hardly read at all in Northern Sotho and not very well in English. Given their weak literacy skills and (compared to the Northern Sotho group) weak phonological skills, one could argue that the phonological skills which normally exist in a reciprocal relationship with reading were not properly developed in the English group. Transfer of phonological knowledge was therefore either not possible or not supportive of the literacy acquisition process. The results questions the theory that transfer of linguistic skills required to read is bidirectional and suggests that transfer from an AL to an L1 may not be beneficial, especially not when languages differ in terms of their orthography and when reading strategies in the AL differ from those required for the L1.

The results of the present study are best interpreted in terms of the Central Processing Hypothesis (Geva and Siegel, 2000). If literacy acquisition does not depend on the nature of the language of instruction, but on the development of common underlying metalinguistic and cognitive processes such as PA, lexical ability, working memory and automaticity, one can conclude that these (or some of these) processes are not properly developed in children who struggle to read. One potential reason why the English group particularly exhibited weaknesses with regard to the mentioned skills is that they lacked sufficient competence in the L2 English. It seems that when literacy instruction initially does not happen in the L1, and knowledge of the L2 is insufficient, learners end up with impoverished phonological abilities in both their languages. The assumption that learners always acquire phonological awareness skills (especially explicit skills) in the language in which they receive their literacy instruction is thus not correct. The present findings suggest that South African learners are at risk of not acquiring the phonological skills associated with reading in any of the languages that they speak - a situation which could partly explain the current literacy problems seen in African learners.

\section{LIMITATIONS TO THE STUDY}

The present study is limited in scope and cannot fully explain reading performance in bilingual Northern Sotho/English children. While PA predicted some of the variance in Northern Sotho and English word reading, other variables such as general language skills, teaching methods, teacher skill and poverty might also have contributed to the reading outcomes. Such variables were not the focus of this study. The study was also limited in that PA was not studied in English and not on phoneme level; had this been done a clearer picture might have presented itself as to how phonological skills affect the acquisition of reading in emergent bilingual children. Further research with a bigger sample is needed to disentangle the relationship between L1 and L2 phonological skills and learning to read simultaneously in Northern Sotho and in English. Finally, the development of phonological awareness should ideally be observed over a period of time. However, such a longitudinal project was beyond the resources available for this initial study.

\section{END NOTES}

1. Northern Sotho is one of eleven official language in South Africa and is spoken as L1 by approximately nine per cent of the population (2001 census data) (http://africanlanguages.com/northern_sotho/; accessed on 20 February 2013).

2. The terms 'Bantu' and 'Southern Bantu' are used as technical linguistic terms to refer to a particular subgroup of languages spoken in Africa. 
3. Initially, the PA task also included items that tested phoneme awareness. These items were excluded from the final analysis as too many learners performed at or near floor level.

4. This could also be explained by the fact that the Northern Sotho group started reading in Northern Sotho one year before they started reading in English.

\section{APPENDIX A}

\section{Items used in Syllable Deletion Task}

Item

\begin{tabular}{|c|l|c|l|}
\hline 1 & Say & Bolelo & Now say it again, but don't say /bo/. \\
\hline 2 & Say & Gabotse & Now say it again, but don't say /ga/. \\
\hline 3 & Say & Letamo & Now say it again, but don't say /mo/. \\
\hline 4 & Say & Morago & Now say it again, but don't say /go/. \\
\hline 5 & Say & Fetola & Now say it again, but don't say /la/. \\
\hline 6 & Say & Batswadi & Now say it again, but don't say /di/. \\
\hline 7 & Say & Polelo & Now say it again, but don't say /le/. \\
\hline 8 & Say & Basadi & Now say it again, but don't say /sa/. \\
\hline 9 & Say & Garafo & Now say it again, but don't say /ra/. \\
\hline
\end{tabular}

2. Items used in Northern Sotho Non-word Repetition Task

\begin{tabular}{|c|c|c|c|}
\hline Four-syllable words & Five-syllable words & Six-syllable words & Seven-syllable words \\
\hline sêpokari & makêpodiri & Môgisirolêtha & hlôdikilêswagoba \\
\hline sêlumaka & nesodiwakô & Katôngwaloshane & nôrakulêswibisi \\
\hline ntômbuwêka & môfugatsadi & Batêraphôtwana & nasibhêkarabilê \\
\hline nthufobila & bosithirangwê & Basêtswêgôkoela & narulôngwakhubasi \\
\hline
\end{tabular}

\section{REFERENCES}

ALCOCK, KJ, D NGOROSHO, C DEUS \& MCH JUKES. 2010. We don't have language at our house: Disentangling the relationship between phonological awareness, schooling and literacy. British Journal of Educational Psychology, 80:55-76.

BADDELEY, AD. 1999. Essentials of Human Memory. East Sussex: Psychology Press Ltd.

BADDELEY, AD. 2003. Working memory: Looking back and looking forward. Nature Review Neuroscience, 4:829-839. 
BERNHART, EB \& ML KAMIL. 1995. Interpreting relationships between L1 and L2 reading: Consolidating the linguistic threshold and the linguistic interdependence hypotheses. Applied Linguistics, 16:15-34.

BISHOP, DVM, CV ADAMS, \& C FRAZIER NORBURY. 2004. Using nonword repetition to distinguish genetic and environmental influences on early literacy development: A study of 6-year-old twins. American Journal of Medical Genetics Part B: Neuropsychiatric Genetics, 129B(1):94 -96.

BRADY, SA \& D SHANKWEILER (Eds). 1991. Phonological Processes in Literacy: A Tribute to Isabelle Y. Liberman. Hillsdale, NJ: Erlbaum.

COETZEE, AW \& WISSING, DP. 2006. Global and Local Durational Properties in Three Varieties of South African English. Linguistic Review.

CUMMINS, J. 2000. Language, power and pedagogy: Bilingual children in the crossfire. Clevedon: Multilingual Matters.

DEACON, H \& K CAIN. 2011. What we have learned from 'learning to read in more than one language'. Journal of Research in Reading, 34 (1):1-5.

DE BREE, E. 2007. Dyslexia and Phonology. Doctoral dissertation. Utrecht University.

DEPARTMENT OF BASIC EDUCATION. 2011. Report on the annual national assessments of 2011. Pretoria: Department of Basic Education.

DOLLOGHAN, C \& TF CAMPBELL. 1998. Nonword Repetition and Child Language Impairment. Journal of Speech, Language, and Hearing Research, 41:1136-1146.

GEVA, E \& LS SIEGEL. 2000. Orthographic and cognitive factors in the concurrent development of basic reading in two languages. Reading and Writing: An Interdisciplinary Journal, 12:1-30.

HOWIE, S, E VENTER, S VAN STADEN, L ZIMMERMAN, C LONG, C DU TOIT, V SCHERMAN \& E ARCHER. 2008. Pirls 2006 Summary Report: South African children's reading achievement. Pretoria: Centre for Evaluation and Assessment. Available:

http://africanlanguages.com/northern_sotho; http://en.wikipedia.org/wiki/Sotho_phonology.

KIM, Y. 2009. Cross-linguistic influence on phonological awareness for Korean-English bilingual children. Reading and Writing, 22:843-861.

LEAFSTEDT, JM \& MM GERBER. 2005. Crossover of Phonological Processing Skills: A study of Spanish-speaking students in two instructional settings. Remedial and Special Education, 26:226-235.

MATJILA, DS \& EJ PRETORIUS. 2004. Bilingual and biliterate? An exploratory study of Grade 8 reading skills in Setswana and English. Per Linguam, 20:1-21.

MOTHIBELI, A. 2005. Cross-country achievement results from the SACMEQ II project 2000 to 2002. A quantitative analysis of education systems in Southern and Eastern Africa. EduSource Data News. No. 49/October 2005. Available: www.edufound.org.za.

NITHART, C, E DEMONT, M METZ-LUTZ, S MAJERUS, M PONCELET, J LEYBAERT. 2011. Early contribution of phonological awareness and later influence of phonological memory throughout reading acquisition. Journal of Research in Reading, 34(3):346363. 
PAULESU, E. 2006. On the advantage of 'shallow' orthographies: Number and grain size of the orthographic units or consistency per se? Developmental Science, 9(5):443-444.

PEFETTI, CA. 1994. Psycholinguistics and reading ability. In M.A. Gernsbacher (Ed), Handbook of Psycholinguistics. Academic Press: New York. 849-894.

PERFETTI, CA, I BECK, L BELL, \& C HUGHES. 1987. Phonemic knowledge and learning to read are reciprocal: A longitudinal study of first grade children. Merrill-Palmer Quarterly, 33:283-319.

PRETORIUS, EJ \& DM MAMPURU. 2007. Playing football without a ball: language, reading and academic performance in a high-poverty school. Journal of Research in Reading, 30(1):38-58.

SHANKWEILER, D \& A FOWLER. 2004. Questions people ask about the role of phonological processes in learning to read. Reading and Writing: An Interdisciplinary Journal, 17:483-515.

SOARES DE SOUSA, D, Y BROOM \& J FRY. 2010. The effects of phonological awareness of Zulu-speaking children learning to spell in English: A study of cross-language transfer. British Journal of Educational Psychology, 80:517-533.

SOARES DE SOUSA, D \& Y BROOM. 2011. Learning to read in English: Comparing monolingual English and bilingual Zulu-English Grade 3 learners. South African Journal of Childhood Education, 1(1):1-18.

VAN ROOY, B \& E J PRETORIUS (2013). Is reading in an agglutinating language different from an analytic language? Southern African Linguistics and Applied Language Studies, 31(3): (to appear).

VEII, K \& J EVERATT. 2005. Predictors of reading among Herero-English bilingual Namibian school children. Bilingualism: Language and Cognition, 8(3):239-254.

\section{BIOGRAPHICAL NOTE}

Dr Carien Wilsenach is a Senior Lecturer in the Departement of Linguistics, Applied Linguistics and Translation Studies at the University of South Africa.

E-mail address: wilseac@unisa.ac.za 